\title{
Role of Social Media Data Analytics in Tourism Marketing
}

\author{
Disha Joshi $^{1^{*}}$, Dr. Raju Rathod ${ }^{2}$
}

\author{
${ }^{1}$ Research Scholar, G. H. Patel Institute of Business Management, Sardar Patel University, Mota Bazaar, Vallabh Vidyanagar, Anand, Gujarat 388120, \\ India \\ ${ }^{2}$ Professor, G. H. Patel Institute of Business Management, Sardar Patel University, Mota Bazaar, Vallabh Vidyanagar, Anand, Gujarat 388120, India
}

DOI: $10.36347 /$ sjebm.2021.v08i01.005

| Received: 09.01.2021 | Accepted: 25.01.2021 | Published: 30.01.2021

*Corresponding author: Disha Joshi

Abstract

Review Article

Social media platforms have been very helpful for the marketers in the tourism industry to track the content generated by users relating to their travel choices, experiences, activities and trending tourist destinations. Such user generated content serves as a reservoir of database for the tourism marketers to identify trends and future demands. Social media data analytics help in framing campaigns for branding as well as enhancing the customers' experiences. Also, the analysis of facts found from the social media help the tourism industry to predict future shifts in consumers' choices. Social media is an inevitable platform for tourism marketing where deeper insights are generated from the existing data by utilizing certain metrics. The social media data analytics must be exploited for increasing brand awareness and innovatively engaging consumers in the tourism industry.

Keywords: Social media analytics, tourism marketing, social media metrics.

Copyright $(\mathcal{C} 2021$ The Author(s): This is an open-access article distributed under the terms of the Creative Commons Attribution 4.0 International License (CC BY-NC 4.0) which permits unrestricted use, distribution, and reproduction in any medium for non-commercial use provided the original author and source are credited.

\section{INTRODUCTION}

Social media has profoundly changed the way the various demographics are targeted by many companies. Due to the increased popularity of social channels, marketing for the travel and hospitality sector, in particular, has altered to a great extent. From the manner in which travelers search potential destinations and the behavior depicted by them, to the activities in which they participate, the consumers use social media extensively to make purchasing decisions. Social media is a vast source of collecting data as facts and evidences since the consumers are consistently involved in creating and contributing content on the internet. The online searches and transactions also add to the richness of information that is collected by the industry. These evidences are real time, which provide an opportunity to monitor and understand what the data is actually trying to convey. Tourism brands are increasingly keeping a track of the vast data generated. Based on the data, brands develop certain insights and take actions that are aligned with the choices and preferences of the consumers, and, eventually develop new means of marketing travel services to consumers. The marketing messages are generally crowdsourced, that is, the agenda developed for marketing is based on certain evidences of content that is generated by a large number of audiences. Evidence based marketing is a practice where the marketing decisions are taken on the basis of real data, instead of generalizing any conclusions based on market research done on a segment of the consumers. Such evidence-based marketing campaigns are agile and are able to shift their perspectives according to the reactions from the audience. The messages and even the target audiences can be altered based on response to the marketing efforts. There is extensive use of technology to measure which creative concepts the audiences are able to connect with, as developing a meaningful connection with the audience is the basis to increase sales [1].

Tour operators need to gather as much information about their consumers as they can in order to understand who they are. The insights about the customers help in targeting the potential prospects through a better and more convincing approach. Tour operators are increasingly spending the advertising money on fact based social media marketing which enables them to track the return on investment. The study aims to understand the contribution of various metrics to understand the data collected from social media. Also, the meaningful information to be extracted from the real-time data can be utilized for tourism marketing, as well as providing customers with enhanced and increasingly personalized services. 
Disha Joshi \& Raju Rathod., Sch J Econ Bus Manag, Jan, 2021; 8(1): 39-43

This paper aims to provide suggestions for travel companies based on theory-related approaches and evidences of the current practices adapted by market leaders to measure brand related activities in the social media domain. In order to understand the themes comprising of social media as a field of data collection and analysis with respect to user generated content and brands activities, an extensive literature review of scholarly articles comprising of related theme was conducted. Hence, the methodology adopted for the paper is a qualitative analysis of the articles pertaining to social media analytics and tourism marketing.

\section{Social Media Data Analytics for Tourism}

Social Media, a powerful source of data can be helpful for tourism marketers in providing real-time insights of the consumers. The data collected through social media can aid in decision-making by offering the tourism marketers with opportunities to gain multiple insights [2]. For example, identifying the posts that have generated much more engagement can aid in deciding what type of content to share. Discovering brand related hashtags that expand the reach to potential visitors could help in increasing the reach of the brand. Achieving a reasonable number of click-throughs means that the followers are engaged with the content and that they might be finding it useful and relevant [3]. The brands can use various metrics to get insights about their followers' actions and responses according to the objective of their online activities. There are multiple metrics, or standards of measurement, that are used to measure the objectives set by tourism brands. According to the matrix in table 1, the metrics can be classified into three broad categories: activity metrics (metrics related to the brands' actions on social media), interaction metrics (metrics that describe how the audience engages with the brand on social media) and return metrics (metrics to measure the success of the brand). Additionally, social media data can be characterized as qualitative and quantitative [4].

Table-1: Framework of Social Media Metrics

\begin{tabular}{|l|l|l|}
\hline Category & Quantitative Metrics & Qualitative Metrics \\
\hline Activity & $\begin{array}{l}\text { Updates/ posts } \\
\text { Comments } \\
\text { Photo posts } \\
\text { Videos posts }\end{array}$ & $\begin{array}{l}\text { Positioning of the brand } \\
\text { Resonance of audience with campaign } \\
\text { Social media involvement }\end{array}$ \\
\hline Interaction & $\begin{array}{l}\text { Likes/ Saves } \\
\text { Comments/ posts/ mentions/ tags } \\
\text { App installs } \\
\text { Channel/ newsletter subscriptions } \\
\text { Followers } \\
\text { Shares/ Refer } \\
\text { Reviews/ testimonials } \\
\text { Views/ Impressions } \\
\text { User Generated Content contributed }\end{array}$ & $\begin{array}{l}\text { Brand sentiment } \\
\text { Engagement } \\
\text { Recommendations on social media } \\
\text { Virality of content }\end{array}$ \\
\hline Return & $\begin{array}{l}\text { Cost } \\
\text { Lead conversion rate } \\
\text { Customer lifetime value }\end{array}$ & $\begin{array}{l}\text { Attitude toward the brand } \\
\text { Brand loyalty } \\
\text { Return on investment }\end{array}$ \\
& $\begin{array}{l}\text { Customer satisfaction } \\
\text { Perceptions towards service quality }\end{array}$ \\
\hline
\end{tabular}

Source: [5]

The travel companies can generate actionable insights for marketers that aid in analyzing marketing and other revenue enhancing initiatives through quantitative models. Due the speed and flexibility, travelers use social media platforms to research, review, recommend, and purchase travel services and packages. Also, instead of focusing on just 'likes', brands also observe the sales made through its social media pages as a result of their efforts to reach out to their online community. The quantitative metrics are used to provide valuable insights, that enable companies to enhance response rates of their campaigns on social media platforms, resulting in achievement of desired business outcomes. Travel companies can leverage social media as a key tool in communicating and marketing to customers. The qualitative metrics help to gauge the success of campaigns on social media platforms by monitoring the brand sentiment as well as social media involvement of its audience.

The social channels are assessed by companies and a baseline measurement is recorded for metrics like what should be the follower count, reach of the post, and how much engagement a particular post must receive. Accordingly, a measurement framework is developed that defines specific metrics that align with key objectives. Table- 2 describes certain objectives that are decided by tourism companies and the metrics that are used to measure those objectives. 
Disha Joshi \& Raju Rathod., Sch J Econ Bus Manag, Jan, 2021; 8(1): 39-43

Table-2: Metrics used by Tourism Companies to Track their Marketing Objectives

\begin{tabular}{|l|l|}
\hline Objective & Metrics \\
\hline Boost audience engagement & $\begin{array}{l}\text { Click through Rates, shares, Likes, comments, Retweets, Favorites, } \\
\text { Hashtag uses }\end{array}$ \\
\hline Increase brand awareness & Followers, Mentions, Brand Sentiment \\
\hline Generation of sales from social media & Click through rates, Ticket sales, Hotel bookings, Newsletter sign ups, etc. \\
\hline Improve targeted marketing & Demographic analysis of followers across various social media accounts \\
\hline $\begin{array}{l}\text { Providing better customer service } \\
\text { through social media }\end{array}$ & Average response time, number of email/ phone inquiries \\
\hline Uncover areas for improvement & Sentiment analysis of reviews, posts and comments by audience \\
\hline
\end{tabular}
Source: [6]

Social media data analytics must be holistically understood by travel companies by aggregating the results of their marketing activities throughout all the social media channels on which they have their presence. However, the target audience can differ from one social media platform to another and hence, companies also consider the unique abilities of each social media platform such as Facebook, Twitter, Instagram or YouTube, respectively to understand their audiences' behavior.

Facebook is the social network that reaches 1.62 billion users every day. The analytics tools of Facebook can segment a brand's audience by various demographics such as age or geographic location. The travel companies can hence add local references or regional information accordingly to appeal to the targeted audience in the market. Also, based on the engagement level, businesses can determine the best times to add new page content [7]. Considering the 'Responsiveness' metric gives evaluation of how often and how fast the company respond to messages on Facebook [8]. Travel companies who work on improving this measure can develop trust and credibility amongst their followers.

Twitter facilitates people to have easy access to information where brands to communicate quickly and concisely without much of formal communication. People can message or tweet at pages to find out more information about a destination. Hashtagging the name of travel destinations categorize and index the tweets, that makes them easily searchable to people who are researching a destination or attraction. The main analytics dashboard of Twitter displays the top Tweet and by clicking "View Tweet activity" specific engagement can be observed which is broken down by link clicks, profile clicks, etc. Similar to the profile visits metric, travel businesses also view their @ mentions over the last 28 days along with tweet count, and impressions for understanding how the tweets perform. The audiences tab of Twitter gives businesses data on who follows its handle. This includes demographics, consumer behaviour, as well as lifestyle information. Such insights of Twitter's audience lead to a better sense of who should be targeted during travel seasons.
Due the vast number of photos and videos shared by its users, Instagram is a more realistic platform for marketing in the tourism industry. Instagram users can engage with the content on the platform by liking, commenting and sharing at a much higher rate than any other platform. Secondly, Instagram's geo-tag feature allows users to search a location and view all of the recent posts shared. The excitement that users feel when they see an appealing image can be channelled into finalizing their travel plans. While scrolling through their image feed on the application, users can click "book now" for the tour packages and offers that interest them [9].

YouTube Analytics provides data about each video that has been uploaded. Data such as how many views are received by the video, where people are coming from to find it and what type of people are watching it can be easily tracked. YouTube Analytics also gives information about the 'firsts' for the video, including the first referral from a related video, first referral from a YouTube search (including the search terms used), and first time the video is embedded in another website. Additional data such as number of views from each referral source along with which gender and age groups the video is most popular with helps the travel companies to create content for audience that resonates with their target audience. YouTube's Subscribers Report shows the videos, locations, and time periods that gain and lose subscribers. This data helps to determine what video topics resonate with the subscribers and where to target new subscribers. By prioritizing the needs of subscribers, the company can create videos that increase watch time, resulting in positively boosted search rankings [10].

\section{User Generated Content on Social Media}

Social media has been the prime platform for people to enable and accelerate people's ability to share travel experiences with a wider audience. Users share their travel experiences on the social media sites by posting photos, videos, links, and other pieces of content that are then shared further by other users. This potential is leveraged by travel businesses to distribute special offers, notifications, updates, and other information about products and services, and thereby enhancing the outreach of the businesses. Due to this 
Disha Joshi \& Raju Rathod., Sch J Econ Bus Manag, Jan, 2021; 8(1): 39-43

trend of sharing travel experiences through photos, videos and verbal content, many hotels and resorts have launched social contests and campaigns to make sure that they are a part of their followers' social activity. Such campaigns urge their followers to shoot photos or videos and use appropriate brand related hashtags to tag them, which ultimately helps to create user generated content for the brand. The content created jointly by the engaged followers in response to the campaigns is free and genuine, which can then be used across the different marketing channels by brands. Also, such content helps the businesses on social platforms to establish credibility with consumers.

Measuring the sentiment of the engaged audience on social media can be used to determine how the audience feels about the brand. It helps to monitor how they are interacting and what are they actually saying about the brand. A sentiment analysis conducted on reviews and social media posts can reveal what the guests feel about their stay. Hotels can identify key words and phrases that are associated with positive and negative sentiments, such as descriptions of room service, and decide on areas of improvement. The use of social media data analytics can thus help to track keywords or phrases included in the positive or negative feedback or reviews that are associated with the brand. Moreover, identifying the right social media metrics helps tourism marketers to find answers for various aspects such as:

- Which demographic to target?

- Which prospects will respond to the campaign of the brand?

- How to convert more prospects into long-term customers?

- How to optimize the investment into campaign by focusing on the right prospects?

- How to compare the characteristics across various segments to determine actions specific to each targeted segment?

- Which products or services are most appropriate?

- What is the best time and channel to offer travel services?

- How to cross-sell offers precisely so that customer fatigue is reduced?

- What are the expectations of various customer segments?

- How to price the inventory (of seats, rooms, etc.) to increase revenue?

\section{Opportunities for tourism marketing through Social Media Data Analytics}

With more and more people travelling and sharing their experiences on social media, the brands can leverage these platforms to understand more about what the consumers want. Every day, marketers come across new user generated data through posts on Facebook, videos shared on YouTube, tweets, and reviews. Marketers equip businesses with additional insight, which in turn provides an opportunity to optimize the returns on investment by leveraging this social data [11].

Social media is the place to find out what the consumers are discussing, as well as handling consumer relationships and public relations. Social data can be a great resource to understand the intended or even, unintended brand advocates. Audience analytics like Affinities or Segments data can help to determine which demographic is following the brand's campaign, and also the kind of interests into which these audiences are involved on social media. Such insights can be leveraged in combination with the equally potent unsolicited data about brand for creating a new, more valuable campaign that consists of a message particularly for the audience with such shared interests [12]. The brands with their presence on social platforms supporting hashtags can encourage their customers to use hashtags in their travel photos and videos. This way brands can get insights on the people's perspectives about their travels through the photos and videos they share. Facebook is such a social network, which allows the brands to target the right demographic. A comprehensive branding and marketing strategy on Facebook can enable the Facebook users to receive advertisements that are parallel to their wants and needs. This helps the brands to achieve a higher engagement rate [13]. Twitter also plays an important role in the social media strategy of brands to spread the word about contests and marketing promotions, and also help customers to get travel alerts.

The tourism brands can transform their customer service and satisfaction through social media. The social media presence of brands can be used to become aware of and help unsatisfied or confused customers. The companies can develop a strong reputation among current and potential customers by responding to complaints in an authentic and sincere manner. Providing a human touch to frustrating experiences and dealing with issues in an interactive way with customers can prove to be advantageous for the brands.

The millennial generation is increasingly inclining their preference for experiences rather than materials. The brands can bundle their products and services that enable their customers to have unique experiences that create memories, instead of trying to upsell upgrades in flights and accommodation. It is imperative to be able to provide a personal touch to the customers, where more and more travel companies are struggling to provide self-booking facilities at every stage of travel booking. Also, brands must capitalize on the available technologies such as TweetDeck, Hootsuite, Google Analytics, Social Mention, etc that allow tracking and social listening across various social media channels [14]. It can be beneficial to study the social conversations going around a specific brand 
Disha Joshi \& Raju Rathod., Sch J Econ Bus Manag, Jan, 2021; 8(1): 39-43

related word through hashtags and social mentions, eventually discovering people who remain engaged with the brands' activities on a regular basis and rewarding them accordingly [15].

\section{CONCLUSION}

Social media has disrupted the landscape of tourism marketing. Majority of travel plans are determined on the basis of reviews and social media shares, which means that online customer service is a vital part of building a positive brand reputation. It is inevitable for travel companies to have their presence across various social media channels to be able to track and collect data and evidences of the content generated related to them. This can aid them to develop marketing plans to target specific consumer interests as well as encourage them to engage with the brands' online activities. Also, responding to the complaints and queries helps in the humanizing of brands and is an indication to the customers that they are valued. By using social media websites to monitor travelers' responses and needs, travel companies can evolve with major disruptions in the industry. Embedding analytics to understand every stage of a customer's lifecycle, businesses get better at predicting a customer's future behavior; eventually leading to a progress in the balance sheet as well as shareholder value. The use of social media analytics to offer distinguished services alongside a unique and satisfying customer experience can differentiate one's product and provide a reason for customers to stay loyal over time.

\section{REFERENCES}

1. evidencebasedmarketing.net, "What Is EvidenceBased Marketing?," [Online]. Available: http://evidencebasedmarketing.net/about-evidencebased-marketing. [Accessed October 2018].

2. Dhiratara A, Yang J, Bozzon A, Houben GJ. Social media data analytics for tourism: A preliminary study. KDWEB 2016. 2016.

3. White B. How To Measure ROI in Travel \& Tourism Digital Marketing, [Online]. Available: https://www.mytravelresearch.com/how-tomeasure-roi-in-travel-tourism-marketing/. [Accessed October 2018].

4. Mike B. Social Media Metrics You Should Be Tracking. 2010. [Online]. Available: https://www.socialmediatoday.com/content/6social-media-metrics-you-should-be-tracking.
5. Tuten T, Solomon M. The Evaluation and Measurement Process: DATA, in Social Media Marketing, SAGE, 2016, 293.

6. Ching E. A Dmo's Guide To Measuring The Roi Of Social Media, February 2017. [Online]. Available: https://crowdriff.com/blog/dmos-guidemeasuring-roi-social-media/. [Accessed October 2018].

7. Kuchinskas S. Social media analytics: 4 ways travel companies can make connections with consumers, September 2015. [Online]. Available: https://www.ibmbigdatahub.com/blog/socialmedia-analytics-4-ways-travel-companies-canmake-connections-consumers.

8. Newberry C. The Beginner's Guide to Facebook Analytics, January 2020. [Online]. Available: https://blog.hootsuite.com/facebook-analyticsinsights-beginners-guide/.

9. Mendes M. How Instagram Has Taken Over Tourism Marketing, [Online]. Available: https://www.pixlee.com/blog/how-instagram-hastaken-over-tourism-marketing/.

10. Chi C. YouTube Analytics: The 15 Metrics That Actually Matter, [Online]. Available: https://blog.hubspot.com/marketing/youtubeanalytics.

11. Davis J. The Social Business: From Data to Insight to Action, January 2012. [Online]. Available: http://evidencebasedmarketing.net/the-socialbusiness-from-data-to-insight-to-action. [Accessed October 2018].

12. Moriarity M. 5 Ways Travel Companies Can Leverage Social Media Analytics, July 2016. [Online]. Available: https://www.crimsonhexagon.com/blog/5-waystravel-companies-can-leverage-social-analytics/. [Accessed October 2018].

13. Cisnero K. Social Media Tips From The Tourism Pros, July 2014. [Online]. Available: https://blog.hootsuite.com/social-media-tips-fortourism/. [Accessed October 2018].

14. Tuten T, Solomon M. Social Media Marketing, New Delhi: Sage Publications India Pvt. Ltd..

15. Carnoy J. 5 Ways Social Media Has Transformed Tourism Marketing, March 2017. [Online]. Available: https://www.entrepreneur.com/article/286408. [Accessed October 2018]. 